\title{
Correction to: COVID-19 in New York City
}

\section{Correction to: \\ D. Wallace, R. Wallace, COVID-19 in New York City, SpringerBriefs in Public Health, https://doi.org/10.1007/978-3-030-59624-8}

The original version of this book was inadvertently published with incorrect captions for Fig. 1.1 of Chapter 1 and Fig. 2.1 and Fig. 2.2 of Chapter 2. It also had an incorrect Fig. 3.1 in Chapter 3. This has now been corrected and an erratum to this book can be found at https://doi.org/10.1007/978-3-030-59624-8_6.

\footnotetext{
The updated online version of these chapters can be found at https://doi.org/10.1007/978-3-030-59624-8_1 https://doi.org/10.1007/978-3-030-59624-8_2 https://doi.org/10.1007/978-3-030-59624-8_3

(C) The Editor(s) (if applicable) and The Author(s), under exclusive license to Springer Nature Switzerland AG 2021

D. Wallace, R. Wallace, COVID-19 in New York City, SpringerBriefs in Public Health, https://doi.org/10.1007/978-3-030-59624-8_6
} C1 